\title{
A Longitudinal Study of Novice-level Changes in Fluency and Accuracy in Student Monologues
}

\author{
Robert W. Long III ${ }^{1}$ \\ ${ }^{1}$ Kyushu Institute of Technology, Japan \\ Correspondence: Robert W. Long III, Kyushu Institute of Technology, Japan. E-mail: long@dhs.kyutech.ac.jp
}

Received: May 10, 2012 Accepted: July 23, 2012 Online Published: August 23, 2012

doi:10.5539/elt.v5n10p129 URL: http://dx.doi.org/10.5539/elt.v5n10p129

\begin{abstract}
Detailed research concerning the issue fluency, specifically relating to pauses, mean length runs, and fluency rates in Japanese EFL learners, is limited. Furthermore, the issue of tracking fluency gains has often been ignored, misunderstood or minimized in EFL educational research. The present study, which is based on six monologues conducted over a school year (2010-2011), focuses on changes in fluency and accuracy concerning students' use of the simple past and present perfect, present perfect progressive, and past perfect verb tenses. Based on the results of a university placement exam, twenty students were selected. Two groups of ten students with the highest and lowest scores were interviewed for period of six months, three times in each school semester. Research aims focus on whether or not there are changes in pausing (duration and frequency), mean length runs, fluency rates and grammatical accuracy between the two groups over the school year. Students were then videotaped concerning how they responded to different questions, which concerned students' past experiences, and views. Results, based on the transcripts of the student monologues, indicated that there was significant improvement relating to the mean length runs, and on one fluency rate, but there were no significant differences in grammatical errors either in percentage of error free clauses or in errors per 100 words between the two groups. The findings help to further our understanding of specific language gains as it relates to fluency and grammatical accuracy in students' unrehearsed speech over a school year.
\end{abstract}

Keywords: fluency, pauses, filled pauses, monologues, pausology, discourse analysis

\section{Introduction}

As English teachers our ultimate goal in English education is to help our students to be fluent. While it is, indeed, important that students have a large vocabulary, a firm grasp on grammar, syntax, and pronunciation, all of this means very little if students can not clearly and quickly express what they need to say. People are not only judged by the content of their speech, but also how they express their ideas. Yet fluency is a complex topic. Indeed, researchers have tried different ways of defining the term, with fluency being understood as (a) rate of speech (e.g. number of syllables per minute of speech, length of run, pause length, silence, false starts, repetitions, and reformulations), (b) complexity, and (c) the learner's preparedness to take risks and to restructure their interlanguages (Lennon, 1990; Foster, Tonkyn, \& Wigglesworth, 2000; Yuan \& Ellis, 2003; Kormos \& Denes, 2004; Luoma, 2004; Ellis \& Barkhuizen, 2005). Proficiency evaluations like the American Council for the Teaching of Foreign Language (ACTFL) also poorly describe the term, much less how fluency changes over time and with more proficiency.

So, what does it then mean to be truly fluent? Despite a great deal of research on fluency in a wide variety of journals over the past twenty years, there are still inadequate evaluations and descriptions regarding the concept. Raupach (1987) notes that fluency tended to be associated with choppy utterances and hesitant and disrupted speech whereas Lennon (1990) saw it as a skill that is different from other linguistic aspects such as memory, syntactic complexity, and pronunciation. The issue of fluency becomes more confused in that native speakers often exhibit many hesitations and pauses which are deemed appropriate. Gregory (2004) argues that the use of pauses should be taught as a skill in speech communication though there are certain norms to be followed if they are to be viewed as effective. However, for this to be effective, specific data has to be gathered as to what constitutes good and bad pausing.

Teaching and evaluating fluency is also problematic due to the subjective and time-consuming nature of evaluation. A second issue is the lack of software applications, texts or tasks that can evaluate and track fluency 
gains. A third problem is obtaining valid data that can adequately describe fluency at novice, intermediate and advanced levels so that teachers can be able to track and evaluate performance. The purpose of this year-long case study is to identify possible differences in between two novice-levels (low and high) as they pertain to fluency, specifically, pausing (frequency and duration), mean length runs, fluency rates, and grammatical accuracy in regard to the participants' use of the past tense. The data as to how these participants improved will help teachers to better identify and address any problems in novice speakers.

\section{Review of Literature}

The discipline of pausology was defined by O'Connell and Kowal (1980) as the behavioral investigation of temporal dimensions in speech. It is important to note that temporal variables in speech production are objective and quantifiable which can help one understand the social and psychological reasons behind particular pauses. Van Donzel and Koopsman-Van Beinum (1996) point out that in prepared speeches and in spontaneous speeches, speakers use pausing strategies to structure the continuation of the discourse. Thus, speakers wait at certain points in order to determine the utterances to follow because the exact content in speech is not fixed as it is in reading texts. While pausing in speeches that are read aloud, have pausing that closely corresponds to syntactic boundaries, Hansson (1998) found that in spontaneous speech, there is a less restricted distribution. Oliveira (2002) further explored pausing phenomena and concluded that pause occurrence and duration is determined more by the cognitive rhythm of speech instead of the content of the information. In short, Oliveira examined patterns of long pauses and short speech bursts with a period of little pausing and continuous speech and concluded that this pattern was based on an encoding cycle which was more reflective of semantic factors rather than syntactic ones.

The research that Riggenbach (1991) conducted showed that the frequency of unfilled pauses is a strong indicator of nonfluency although these pauses need to be further differentiated according to place and function. Richards et al., (1992: 267) defined pausing as "a commonly occurring feature of natural speech in which gaps or hesitations appear during the production of utterances." Their studies have also examined pausing as they occur in reading, speaking, and between the genders, and the results indicated that pauses generate the listener's expectation about prospective utterances, and signal emphasis. What remains to be seen is whether or not the frequency of pauses is tied to ungrammatical English or if the pauses are used to fill-in particular words or just to give the speaker time to reflect on what to say next.

Lewin et. al (1996) examined pauses and verbal disfluencies as an indication of speaking anxiety. The authors investigated as to whether speech disruptions, periods of silence, and a slower rate of speech were more prevalent in high-speech subjects than in their low-anxiety counterparts. After examining categories of pauses, pause-length, verbal errors (corrections, distortions, fragments, repetitions) and delaying verbalizations, Lewin found that the measures of state anxiety immediately before and during the speech task did not correlate with dysfluencies or pauses. The conclusion was that pausing maybe be a form of escape.

For research purposes, Wendel (1997) and Yuan and Ellis (2003) used a fluency measure that takes into both the amount of speech and length of pauses. The first measure, Rate A, examines the number of syllables per minute (which is divided by the number of seconds used to complete the task multiplied by 60 ) whereas the second measure, Rate B, is based on the number of meaningful syllables per minute but without any syllables or words that were repeated, reformulated or replaced. To sum up, uncertainty does exist in identifying the specific differences among the three novice levels of Japanese false beginners. Clearly, what is needed is a study that investigates the specific aspects of speech rates, mean length runs, pause duration and frequency, and verbal dysfluency, particularly among Japanese EFL learners.

\section{The Study}

\subsection{Purpose}

Preliminary research (Long and Tabuki, 2010) was carried in 2009 as it related pauses as they occurred in student interviews. The aim of this study was to identify the frequency, duration and placement of the pauses in the interviews as well as to identify particular grammatical errors that were closely related to the pauses. The results indicated that grammatical errors were associated to pauses preposition deletions, repetitions, and omissions. Furthermore, it was clear that there were distinct differences between the students who were more proficient (novice-high) as compared to those who could be considered (novice-low) students, specifically as it related to pause duration, frequency and mean length runs. The study did not, however, focus on pauses and particular grammatical usage. 
Specifically, the focus of this study will be on pausing (frequency and duration), mean length runs, fluency rates, and the correct and incorrect usage of the past tense in Japanese first-year university students. By better understanding how fluency and pausing change over a year in a university English program (one lesson per week), teachers can more effectively focus their teaching strategies and tasks for their own students who are at this level.

\subsection{Hypotheses}

The data is to be examined for potential differences relating to pauses, mean length runs, and fluency rates of A and B for the twenty subjects. There are two research questions, concerning fluency and grammatical accuracy, which are based on the six sessions over the school year of 2010-2011, concerning the two groups of students having both high and low proficiency.

1. Will there be any significant differences between high and low-proficiency EFL Japanese speakers in regard to data concerning articulation rates, mean length runs, fluency rates (A and B), pause duration and pause frequencies?

2. Will there be any significant differences between the high and low-proficiency EFL Japanese speakers in regard to the use of the past tense verb forms?

\subsection{Participants}

This study involved the first-year Japanese university students, engineering majors, who were taking an obligatory first year English conversation course. Students were aged from 18-19. The 20 students were from two classes that had been organized based on the results of a university placement exam. The exam was based on 40 questions related to vocabulary, 12 questions related to reading comprehension, and eight questions relating to language use. The two classes were formed based on the scores of the students. One class had students who had scored the highest, (48 to 45 points) with another class representing students who had the lowest scores (33 to 13).

\subsection{Materials and Procedures}

This preliminary case study examines the issue of pauses as they occur in monologues; the 20 students (10 for each group) were videotaped beginning in May of 2010, until their last English class in February of 2011. At an initial meeting, participants gave informed consent, and the participants did not know of the topic beforehand and were informed that the data would be used for educational and research purposes. The participants were asked to answer six different questions, and in total they spoke for a total of 262.6 minutes (4.37 hours), with the low fluency students, as a group, speaking 1 hour and 38 minutes ( 8.2 minutes per person) while high fluency students spoke for 2 hours and 99 minutes (17.9 minutes per person).

\subsection{Data Analysis}

The software utilized in the study was Audacity 1.2 a comprehensive digital audio editor. The data utilized in the analysis was actualized in two stages: (1) the videotaped of each student was played in Quick Time Player 7.6 which was then digitized by Audacity in order to deter the exact length of time the participants spent speaking. The speech waves were extracted at $44100 \mathrm{~Hz}$. By examining the spectrograms of each monologue, it was possible to identify the duration of pauses in milliseconds. The measurements were then put into a statistical analysis program, SPSS 11.5 (Statistical Package for the Social Sciences), for means and means comparisons. In addition to looking at pause frequency, duration, and mean length runs, there were two additional measures for fluency (Rates A and B) as identified by Wendel, (1997). Mean length runs are calculated as the mean number of syllables produced in utterances between pauses of 1.0 and above. Japanese words along with unintelligible words were not counted.

\section{Results}

\subsection{Fluency Data}

In examining the descriptive data as it relates to fluency, it appears that the percentage of silence increased for the high fluency group whereas the lower fluency group made marginal progress. As for mean length runs, both groups showed decreased word lengths between pauses over the six sessions whereas there were varying differentials between fluency rates A and B for both groups. For the time that students spoke, the only marked contrast was that the lower fluency group doubled the time that they spoke. 
Table 1. Descriptive data for fluency indicators

\begin{tabular}{|c|c|c|c|c|c|c|c|}
\hline \multicolumn{2}{|c|}{ Sessions Silence \% } & MLR & AR & TT & F. Rate A & F. Rate B & Differential \\
\hline & $\overline{\mathrm{High} / \mathrm{Low}}$ & $\overline{\text { High/Low }}$ & $\overline{\text { High/Low }}$ & $\overline{\mathrm{High} / \mathrm{Low}}$ & $\overline{\mathrm{High} / \mathrm{Low}}$ & High/Low & High/Low \\
\hline & $40.0 / 58.6$ & $11.5 / 6.1$ & $1.63 / 1.8$ & $193.4 / 86.1$ & $59.0 / 44.1$ & $51.0 / 38.5$ & $8.0 / 5.6$ \\
\hline & 39. & 163 & & & / 51.5 & & $.6 / 7.1$ \\
\hline & & & & & $57.6 / 28.4$ & & $13.4 / 5.6$ \\
\hline & $50.8 / 60.8$ & $6.4 / 5.2$ & $1.9 / 1.5$ & 192.9 & $57.8 / 62.2$ & 49.5 / 52.1 & $8.3 / 10.1$ \\
\hline & & & & & $54.1 / 50.6$ & $50.3 / 42.4$ & $3.5 / 7.9$ \\
\hline & $53.1 / 55.8$ & $5.8 / 5.0$ & $1.9 / 1.9$ & $185.4 / 172.9$ & $57.0 / 52.0$ & $57.2 / 53.5$ & $5.0 / 3.7$ \\
\hline
\end{tabular}

Note. $\mathrm{MLR}=$ mean length run. $\mathrm{AR}=$ articulation rate. $\mathrm{TT}=$ time talking. In regard to fluency rates $\mathrm{A} / \mathrm{B}, \mathrm{a}$ lower score in fluency rate B, indicates increased fluency, whereas a higher differential between fluency rates A and B indicates more fluent speech.

In order to see if the normality condition is met in regard to comparing the two groups, the Jarque-Bera test was conducted concerning the six dependent variables. The results, see table 2, indicate that a nonparametric method (Mann-Whitney $U$ ) was needed to determine significance as one or both groups did not show a normal distribution.

Table 2. Results concerning normality

\begin{tabular}{lrl}
\hline & Jarque-Bera & Probability \\
Articulation Rate & 12.60 & 0.0018 \\
High & 1026.228 & 0.0000 \\
$\quad$ Low & 39.89 & 0.000 \\
Mean Length Runs & 613.58 & 0.000 \\
$\quad$ High & & \\
$\quad$ Low & 2.604 & 0.2719 \\
Fluency Rate A & 10.509 & 0.0052 \\
$\quad$ High & & \\
$\quad$ Low & 5.918 & 0.051 \\
Fluency Rate B & 18.204 & 0.0001 \\
$\quad$ High & & \\
$\quad$ Low & 16.498 & 0.0002 \\
Pause Frequency & 18.797 & 0.0000 \\
$\quad$ High & & \\
Low & 44.212 & 0.0000 \\
Pause Duration & 3.365 & 0.185 \\
$\quad$ High & & \\
Low & & \\
&
\end{tabular}

A Mann-Whitney $U$ test was carried out between the low and high fluency groups on articulation rate, mean length runs, fluency rates $\mathrm{A}$ and $\mathrm{B}$, duration of pauses, and frequency of pauses. The test, with significance set at 0.1 , showed that there was no difference in the articulation rate between the two groups and duration of pauses. The test showed a highly statistically significant different in mean length runs, fluency rate A, fluency rate B, and frequency of pauses, see table 3.

Table 3. Mann-Whitney results

\begin{tabular}{lllllll}
\hline Group & AR & MLR & Rate A & Rate B & P.D. & P.F. \\
$U$ & 1732.5 & 990.5 & 1170.5 & 1201.5 & 1436.5 & 1435 \\
$Z$ & 0.3549 & 4.250 & 3.067 & 2.901 & 1.637 & 1.645 \\
Asymp. Sig & 0.7227 & 0.000 & 0.0022 & 0.0037 & 0.1015 & 0.0999
\end{tabular}

Note. $\mathrm{AR}=$ articulation rate, $\mathrm{MLR}=$ mean length runs, $\mathrm{PD}=$ pause duration, $\mathrm{PF}=$ pause frequency. 
From this data it can be concluded that there is a statistically significant difference between the two groups in how often they pause, their actual fluency, particularly in how long they are able to talk between pauses, but that there is little difference in how long the two groups pause, and in their actual articulation rate. In examining the data concerning pause duration, there was a significant difference in the averages between the two groups for the first session (low $=11.1$ seconds, high $=5.3$ seconds), but this difference for the following sessions narrowed to around one second between the two groups, with the average duration ranging being between 3.4 to 5.3 seconds.

Fluency can also be examined in regard to micropauses. Long \& Tabuki (2010) found in a preliminary study that novice low speakers used only a total of 18 micro-pauses ( $9.2 \%$ of the total), as compared to novice mid speakers who had 76 (38.9\%) and novice high speakers who had 101 micro-pauses (51.9\%). In this year's data, it was clear that more proficient speakers used two or three times more micropauses than lower level speakers. Over the six sessions, the average number of micropauses were as follows for the higher fluency group, 9.3, 9.6, 12.0, 8.2, 9.8 and 8.3, whereas for the lower fluency group, it was much lower-1.6, 3.9, 3.8, 5.7, 6.9 and 6.5. This data indicates that as proficiency increases, the pauses may decrease in duration to micropauses, which are still numerous and more difficult to perceive.

\subsection{Grammatical Accuracy Data}

Coding, for incorrect verb form usage included wrong tense, morphed verb forms, and incorrectly used verb forms. Repeated verb forms were also counted. In answering the third research question concerning significant differences, between the two groups, in regard to the students' use of past verb forms over the six sessions, the data in the tables 3 and 4 indicate that there were significant differences noted in the first, second, fourth, fifth sessions and for the average for all of the sessions in participant's correct usage of the past tense. It should be noted that the higher fluency group did use the simple past tense a great deal more, both correctly and incorrectly, whereas there were far fewer cases of incorrect and correct usage of this tense among the lower fluency students.

As for incorrect usage of the participants' past tense, there were no significant differences among all of the sessions or with the average. As for the low fluency group, the present perfect tense were used correctly three times over the six sessions, and incorrectly two times during one session. The present perfect progressive, past perfect progressive, past progressive, and past perfect were not used during any of the sessions in this group. In the high fluency group, students rarely used were other forms of the past tense: present perfect (9), past perfect (1), present perfect progressive (1), and past progressive (1). The data was further analyzed by examining the percentages of error-free clauses (C-units) across the six sessions (see table 3 ) and by errors per 100 words (Mehnert, 1998), see table 4. In analyzing on the C-unit basis, it was difficult to precisely identify the beginning and end of a particular clause due to the unintelligible words, filled pauses, the use of L1, and the repetitious and fragmentary nature of impromptu oral speech. As production (time-speaking) was less with the lower fluency group, the standard deviation was lower 9.56 than that of the higher fluency group 15.4 which spoke longer, thus had more variation in the percentage of error-free clauses.

Table 4. Percentage of error-free clauses for the six sessions

\begin{tabular}{llllllll}
\hline \% of error free clauses & 1 & 2 & 3 & 4 & 5 & 6 & Average \\
Low Fluency & 17.9 & 5.4 & 9.2 & 25.9 & 1.0 & 3.6 & 10.5 \\
High Fluency & 44.0 & 13.0 & 5.0 & 22.0 & 10.1 & 1.7 & 15.9
\end{tabular}

Further analysis involved examining errors per 100 words. Repetitions and the names of all Japanese proper nouns were counted, and contractions were counted as one word. A T-test shows that per 100 words $(\mathrm{M}=.-5.4$, $\mathrm{SD}=11.65 ; \mathrm{t}(5)=-1.14, \mathrm{p}=.302)$.

Table 5. Errors per 100 words for the six sessions

\begin{tabular}{llllclcl}
\hline Error rates & 1 & 2 & 3 & 4 & 5 & 6 & Average/ 100 \\
Low Fluency & 3.3 & 0.6 & 1.7 & 4.5 & 0.1 & 0.6 & 1.69 \\
High Fluency & 6.5 & 1.4 & 0.4 & 3.3 & 1.0. & 09 & 2.11
\end{tabular}

Correct usage of the past tense for the low fluency group was 3.7\% whereas incorrect usage was $1.8 \%$. For the high fluency group, the percentage of correct usage of the past tense was $5.4 \%$ as compared to $2.2 \%$ for incorrect 
usage. There were no significant differences between the two groups in errors per 100 words $(\mathrm{M}=.31, \mathrm{SD}=1.70$; $\mathrm{t}(5)=.453, \mathrm{p}=.669)$. The descriptive data also provided more information about the low fluency group with standard deviations concerning incorrect usage of the verbs ranging from .96 to 9.46 whereas for the higher fluency group the difference was between .51 to 5.21 . This seems to indicate that there was more variation in student ability in the lower fluency group.

\section{Discussion}

It was apparent that students' pauses did decrease as their ability and confidence increased, but when the two groups did pause, it was relatively for the same length of time. When speaking, the rates for both groups were similar; this indicates that increases in fluency are more related with mean length runs and fewer errors and repetitions in one's speech. As for grammatical usage, it was apparent that lower level proficiency students make fewer attempts at varied usage of past (or even present) tense forms, and that teachers will have to be ready to encounter a wider range of abilities and problems with lower level students. The data also makes clear as how difficult it is to note actual progress in regard to fluency over multiple sessions much less to give adequate and meaningful feedback to students.

In sum, it was clear that important distinctions existed at the novice level of fluency. So it is important for teachers to give feedback to students about their own MLRs and their own pausing so as to focus on producing increasingly longer chunks of speech. Furthermore, the implication from Yuan and Ellis' (2003) study on language pedagogy concerning the benefit of giving learners time to plan for tasks was that teachers and testers should endeavor to ensure situational authenticity. Bachman and Palmer (1996) state that learners should be asked to engage in tasks under the same conditions they will experience in the real world. As in the real-world, there is limited time for planning out one's thoughts, so teachers should also provide a similar context. The key for teachers is deciding on which situational contexts, speakers, language notions, functions and forms, and pragmatic issues are the most relevant for their own students.

\section{Conclusion}

This case study examined possible differences in monologues of Japanese EFL learners. The results, based on data about pausing frequency, duration and mean length runs between the two groups of novice-level speakers, emphasizes that people will associate students' fluency more with their overall mean length runs, and their accuracy and lack of repetition in their speech. It must be said, however, that without some form of videotaped feedback (or transcripts), the extent of students' shortcomings will not be easily apparent to both the students and teacher. Teachers should help students to pay more attention to pause duration, repetition, the use of fillers of their speech through the use of videotapes and transcripts. More fluency-based tasks can also be introduced in the classroom such as mocking tasks (repeating and extending on what was said), timed speeches, shadowing, and fluency reviews in which students focus on asking and answering questions at a faster interval.

The results in this case study do lead to more questions. Do teaching strategies and tasks influence fluency? How is the progress of intermediate level speakers different from that of novice-level speakers? Do foreign students have similar problems? How does the data differ in regard to dialogues? The answers to these questions will help unlock more doors so that students can be proficient in English as well as truly fluent. In sum, these results indicate that while students may be familiar with various grammatical forms, their ability to use these forms in impromptu speech is marginal. Also gains in fluency are marginal over one school year. Teachers should, therefore, pay more attention to fluency and to grammatical accuracy in unrehearsed speech.

\section{References}

Bachman, L., \& Palmer, A. (1996). Language testing in Practice: Designing and developing useful language tests. Oxford: Oxford University Press.

Chambers, F. (1997). What do we mean by fluency? System, 25(4), 535-544. http://dx.doi.org/10.1016/S0346-251X(97)00046-8

Ellis, R., \& Barkhuizen, G. (2005). Analysing learner language. Oxford: Oxford University Press.

Foster, P., Tonkyn, A., \& Wigglesworth, G. (2000). Measuring spoken language: A unit for all reasons. Applied Linguistics, 21, 354-375. http://dx.doi.org/10.1093/applin/21.3.354

Gregory, H. (2004). Public speaking for college and career. New York: McGraw-Hill.

Hansson, P. (1998). Pausing in spontaneous speech. In P. Branderud, \& T. Hartmut (Eds.), Proceedings of FONETIK, 98, The Swedish Phonetics Conference, 158-161. 
Kormos, J., \& Dénes, M. (2004). Exploring measures and perceptions of fluency in the speech of second language learners. System, 32, 145-162. http://dx.doi.org/10.1016/j.system.2004.01.001

Lennon, P. (1990). Investigating fluency in EFL: a quantitative approach. .Language Learning, 40, 387-417. http://dx.doi.org/10.1111/j.1467-1770.1990.tb00669.x

Lewin, M. McNeil, D., \& Lipson, J. (1996). Enduring without avoiding: Pauses and verbal dysfluencies in public speaking fear. Journal of Psychopathology and Behavioral Assessment, 18(4), 387-402.

Long, R., \& Tabuki, M. (2010). Pausology and interview questions: A case study. KASELE Bulletin, 38, 19-32.

Luoma, S. (2004). Assessing speaking. Cambridge: Cambridge University Press. http://dx.doi.org/10.1017/CBO9780511733017

Mehnert, U. (1998). The effects of different lengths of time for planning on second language performance. Studies in Second Language Acquisition, 20, 83-108. http://dx.doi.org/10.1017/S0272263198001041

O’Connell, D. C., \& Kowal, S. (1980). Prospectus for a science of pausology. In H.W. Dechert, \& M. Raupach (Eds.), Temporal variables in speech: Studies in honour of Fireda Goldman-Eisler (pp. 3-10). The Hague: Mouton. http://dx.doi.org/10.1515/9783110816570.3

Oliveira, M. (2002). Pausing strategies as means of information processing in spontaneous narratives. Proceedings of the International Conference Speech Prosody, 2002, Aix-en-Provence, Retrieved December, 20, 2011, from http://aune.lpl.univ-aix.fr/sp2002/pdf/oliveira.pdf

Richards, J. C., Platt, J., \& Platt, H. (1992). Longman dictionary of language teaching, Applied Linguistics. Longman, Harlow, Essex.

Raupach, M. (1987). Procedural Knowledge in Advanced Learners of a Foreign Language. In J. Coleman, \& R. Towell (Eds.), The advanced language learner (pp. 123-56). London: CILTR.

Riggenbach, H. (1991). Toward an understanding of fluency: a microanalysis of nonnative speaker conversations. Discourse Processes, 14, 423-441. http://dx.doi.org/10.1080/01638539109544795

Skehan, P. (1996). Second-language acquisition research and task-based instruction. In J. Willis, \& D. Willis (Eds), Challenge and change in language teaching. Oxford: Heinemann. pp. 17-30.

Van Donzel, \& Koopsman-Van Beinum. (1996). Pausing strategies in discourse in Dutch. Retrieved December 20 , 2011, from https://docs.google.com/viewer?a=v\&q=cache:s0TPJpIGFDAJ:www.asel.udel.edu/icslp/cdrom/vol2/505/a5 05.pdf+Van+Donzel+and+Koopsman-Van+Beinum+(1996).+Pausing + strategies + in + discourse + in + Dutch\& hl=en\&pid=bl\&srcid=ADGEESgV2aHpWF9ZILIPtbEK7o37HMFM74xnGgChRtg8zvGzh1uwrpaTT2Gh DBPDB2TttuKrl1Vf1Csv-mi1GtMt0iIvCy-NvaeWfZHcRiRS7u51mwxWzILhNbykW WP1Ru-2X2v6 -t \&sig=AHIEtbTjK4fE2jZC8Dtfj_sQbYZ4Rm9wMw

Wendel, J. (1997). Planning and second language narrative production. Unpublished doctoral dissertation, Temple University, Japan.

Yuan F., \& Ellis, R. (2003). The effect of pre-task planning and on-line planning on fluency, complexity and accuracy in L2 monologic oral production. Applied Linguistics, 24(1), 1-27. http://dx.doi.org/10.1093/applin/24.1.1

\section{Notes}

1. Time speaking for low fluency and high fluency groups.

First session: Low fluency: 14.3 minutes. High fluency: 32.2 minutes.

Second session: Low fluency: 21.6 minutes. High fluency: 21.8 minutes.

Third session: Low fluency: 21.7 minutes. High fluency: 21.8 minutes.

Fourth session: Low fluency: 27.3 minutes. High fluency: 31.1 minutes.

Fifth session: Low fluency: 26.8 minutes. High fluency: 31.2 minutes

Sixth session: Low fluency: 28.8 minutes. High fluency: 30.4 minutes. 
2. T-Tests for First and Last Sessions

(1) Amount of Silence

\begin{tabular}{lllllc}
\hline & Mean & $\begin{array}{l}\text { Std. } \\
\text { Deviation }\end{array}$ & St. Error Mean & T-Ratio & $\begin{array}{l}\text { Sig- } \\
(2-t a i l e d)\end{array}$ \\
\hline Amount of silence & -35.7700 & 63.02078 & 14.09188 & -2.538 & .020 \\
\hline Frequency of pauses & -16.4500 & 4.03503 & 4.03503 & -4.077 & .001 \\
\hline Mean length runs & 3.3850 & 4,19485 & .91787 & 3.688 & .002 \\
\hline Fluency Rate A & -5.5900 & 27.29688 & 6.10377 & -.916 & .371 \\
\hline Fluency Rate B & -5.7700 & 27.81268 & 6.21911 & -.928 & .365 \\
\hline
\end{tabular}

3. The database can be retrieved at: https://sites.google.com/site/fluencyandpauselogy/2011-monologue-data

\section{Acknowledgements}

Thanks are due to the anonymous reviewers of this paper who offered valuable comments and to my colleague, Professor Takashi Tsuji for his suggestions as well.

\section{Author}

Robert Long is an Associate professor at Kyushu Institute of Technology, and has worked as the co-editor for Language Teacher, continues to serve on the TLT Editorial Advisory Board, and to review the JALT Proceedings and for the Kyushu Academic Society of English Language Education. He has published numerous EFL textbooks on reading, speaking, and technical English. His interest areas include pragmatics, pausology, discourse analysis, and material writing.

\section{Appendix 1. Transcripts}

High Fluency

\section{Clip 1. Y. K. Monologue}

Fluency Measures

\begin{tabular}{|c|c|c|c|}
\hline Total Time: & $2: 18.50$ minutes, & Average mean length run: 12.0 & lables \\
\hline Amount of Silence & 86.6 seconds & Articulation rate: 1.84 & \\
\hline Percentage-Silence & $62.5 \%$ silence & Fluency Rates & Rate B: 38.5 \\
\hline \multicolumn{4}{|l|}{ Accuracy Measures } \\
\hline \multicolumn{2}{|c|}{ Correct Past Tense Verb forms } & 3 & \\
\hline \multicolumn{2}{|c|}{ Incorrect Past Tense Verb forms } & 4 & \\
\hline
\end{tabular}

1 In high school, I learned reading, speaking and grammar, but

2 speaking is uh, (1.3) little (2.5) so I I: I am not good at (.) speaking

3 English (3.6) and I learned (.) English for two months entrance

4 examination so (.) I don't get used to (.) speaking English (7.1) and

5 (.) I I learned a lot of vocabulary (18.5) ando I: and watch I ss:

$6 \quad$ (14.1) summer homework (.) is reading English books and (39.5) I

7 don't remember anymore. 
Low Fluency

Clip 1: S. S. Monologue

Fluency Measures

\begin{tabular}{llll}
\hline Total Time: $\quad 2: 10.00 \quad$ minutes, 130.00 & Average mean length run: 5.1 syllables \\
\hline Amount of Silence & 83.4 seconds & Articulation rate: 1.43 & \\
\hline Percentage-Silence $\quad 64.1 \% \quad$ silence & Fluency Rates & Rate A: 30.9 & Rate B: 18.0 \\
\hline Accuracy Measures & & & \\
\hline Correct Past Tense Verb forms & 2 & \\
\hline Incorrect Past Tense Verb forms & 2 & & \\
\hline
\end{tabular}

1 Ah, eh, I studied ah (2.4) many many story (1.5) high school's text 2 in high school's text, (1.1) for example, moving story, eh:, (4.1) text,

3 (word) Japanese, (.) heh heh, eto, (6.7) eto (16.5) I I:: (6.4) hhh (13.7)

4 eto, I I make (2.4) I make (6.2) I made sentence many word, with

5 many words, eh hhh (14.2) ah: high school, lasto (2.8) lasto high

6 school lasto (5.4) ah, hhh.

\section{Appendix 2. CA Transcription Symbols}

\section{Manner/Quality}

Smile quality $\quad £$

Exhale / inhale hhh

vocalism (sniffle)

click .t

laugh pulse heh

laughing word wo(h)rd

laughter heh heh

Low pitch $\downarrow$

High pitch $\uparrow$

pause, timed (1.2)

4. pause, short

lag (prosodic length / elongated sound) :

unintelligible ( )

uncertain (word)

Emphatic tone !

Interviewer comment [[ ] ] 